\title{
Development and Validation of a Score to Predict Postoperative Respiratory Failure in a Prospective Multicentre European Cohort
}

Running head: Prediction of Postoperative Respiratory Failure

\author{
Jaume Canet M.D., PhD. \\ Chairman. Department of Anaesthesiology and Postoperative Care Unit \\ Hospital Universitari Germans Trias i Pujol. Badalona. Barcelona. Spain \\ Sergi Sabaté M.D., PhD. \\ Staff Anaesthesiologist. Department of Anaesthesiology, Fundació \\ Puigvert. Barcelona, Spain \\ Valentín Mazo M.D.
}

Staff Anaesthesiologist, Department of Anaesthesiology, Hospital Universitari Germans Trias i Pujol, Badalona, Barcelona, Spain

\section{Lluís Gallart M.D., PhD.}

Associate Professor. Department of Anaesthesiology, Hospital del Mar IMIM (Institut Hospital del Mar d'Investigacions Mèdiques).

Universitat Autònoma de Barcelona. Barcelona, Spain

Marcelo Gama de Abreu M.D., PhD.

Professor and Head of Research and Pulmonary Engineering Group

Department of Anaesthesiology and Intensive Care Medicine.

University Hospital Carl Gustav Carus, Technische Universität Dresden, 
Dresden, Germany

Javier Belda M.D., PhD.

Professor and chairman. Department of Anaesthesia and Critical Care

Hospital Clínico Universitario, University of Valencia. Valencia, Spain

Olivier Langeron M.D., PhD.

Professor. Department of Anaesthesiology and Critical Care, Université

Pierre et Marie Curie-Paris VI, CHU Pitié-Salpêtrière. Paris, France

Andreas Hoeft M.D., PhD.

Professor and chairman. Department of Anaesthesiology and Intensive

Care Medicine. University of Bonn. Bonn, Germany

Paolo Pelosi M.D.

Professor and chairman. Department of Surgical Sciences and Integrated Diagnostics, IRCCS San Martino Hospital-IST, University of Genoa. Genoa, Italy.

For the PERISCOPE group*

* Members of the PERISCOPE (Prospective Evaluation of a RIsk Score for postoperative pulmonary COmPlications in Europe) group are listed in the Appendix. 


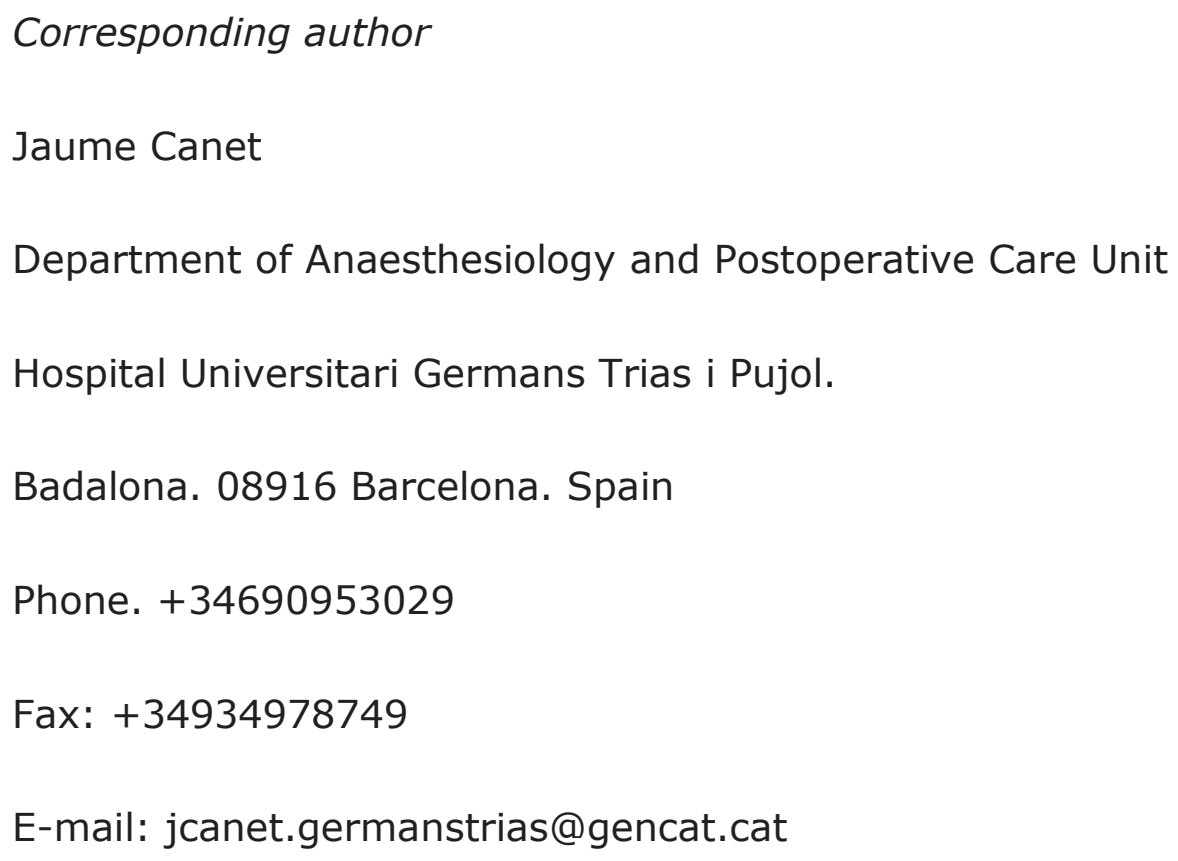

Financial support: The PERISCOPE study was funded and supported through the European Society of Anaesthesiology's Clinical Trials Network.

Word count: Abstract 278, Manuscript 3190. 


\begin{abstract}
Background: Postoperative respiratory failure (PRF) is the most frequent respiratory complication after surgery.
\end{abstract}

Objective: To build a clinically useful predictive model for PRF.

Design: Prospective observational study of a multicentre cohort.

Setting: Sixty-three hospitals across Europe.

Patients: Patients undergoing all surgical procedures under general or regional anaesthesia during 7-day recruitment periods.

Main outcome measures: Development of PRF within 5 days of surgery. PRF was defined by a partial pressure of oxygen in arterial blood $\left(\mathrm{PaO}_{2}\right)<60$ $\mathrm{mmHg}$ or new-onset oxyhaemoglobin saturation measured by pulse oximetry $\left(\mathrm{SpO}_{2}\right)<90 \%$ in room air requiring conventional oxygen therapy, or noninvasive or invasive mechanical ventilation.

Results: PRF developed in 224 (4.2\% of the 5384 patients studied). Inhospital mortality was higher in patients with PRF $(10.3 \%$; $95 \%$ confidence interval $[\mathrm{CI}], 6.3 \%-14.3 \%)$ than in those without PRF $(0.4 \% ; 95 \% \mathrm{CI}$, $0.2 \%-0.6 \%)$. Regression modelling identified a predictive PRF score including 7 independent risk factors: low preoperative $\mathrm{SpO}_{2}$, at least 1 preoperative respiratory symptom, preoperative chronic liver disease, history of congestive heart failure, open intrathoracic or upper abdominal surgery, surgical procedure lasting at least 2 hours, and emergency surgery. The area under the receiver operating characteristic curve (cstatistic) was 0.82 (95\% CI, 0.79-0.85) and the Hosmer-Lemeshow goodness-of-fit statistic was $7.08(P=0.253)$. 
Limitations: Follow-up ended at hospital discharge, the cohort was recruited by volunteer hospitals that did not cover all of Europe, and external validation of the index was not performed.

Conclusions: A risk score based on 7 objective, easily assessed factors was able to predict which patients would develop PRF. The score can potentially facilitate preoperative risk assessment and management and provide a basis for testing interventions to improve outcomes.

The study was registered at ClinicalTrials.gov (identifier, NCT01346709). 


\section{Introduction}

Postoperative respiratory failure (PRF) is the most frequent postoperative pulmonary complication (PPC) with major impact on outcome and health costs. ${ }^{1-7}$ The pathogenesis of PRF depends on factors related to patient status as well as anaesthetic and surgical procedure..$^{8-10}$ The incidence of PRF in general surgical populations ranges between $0.2 \%$ and $3.4 \%{ }^{8}$ and several scores for predicting PRF have been proposed. ${ }^{1,3-7,11}$ However, previous studies developing scores to predict PRF defined this complication differently. Definitions that have been used include unexpected reintubation, $1,5,7,11$ need for postoperative mechanical ventilation ${ }^{1,3}$ or postoperative acute lung injury and acute respiratory distress syndrome (ALI/ARDS). ${ }^{4,6}$ In addition, most of the scores available have been developed with retrospective databases that contain administrative information and coding. ${ }^{1,3,5-7,11}$ Retrospectively identified predictors have certain limitations, ${ }^{12-15}$ including low positive predictive values and moderate reliability, and they are subject to errors in data collection, higher percentages of missing values, and lack of information on variables of clinical interest.

Current thinking on the diagnosis of PRF calls for using objective measures of newly developing hypoxaemia detected during the postoperative course: ${ }^{8}$ specifically, partial pressure of oxygen in arterial blood $\left(\mathrm{PaO}_{2}\right)$ must be less than $60 \mathrm{mmHg}$, a condition that normally corresponds to arterial oxygen saturation less than $90 \%$. Furthermore, according to the most recent international consensus on ARDS, the severity of PRF may be further classified as mild, moderate, or severe based on the ratio of $\mathrm{PaO}_{2}$ to the inspiratory oxygen fraction $\left(\mathrm{FIO}_{2}\right) .{ }^{16}$ Stratifying risk for different degrees of 
PRF severity would potentially facilitate early detection and management of this complication.

In this study, we used a large European database of general surgery cases (PERISCOPE cohort - Prospective Evaluation of a RIsk Score for postoperative pulmonary COmPlications in Europe $)^{17}$ created to externally validate the ARISCAT risk score for a PPC composite. Hypothesising that it would be possible to use the PERISCOPE data to build a simple risk score to predict PRF alone, we designed the present secondary analysis. Our aims were to identify perioperative risk factors for PRF and build and internally validate a specific predictive model. We also stratified PRF at 3 levels of severity based on the presence of hypoxaemia and type of respiratory support in order to assess differences in outcome. 


\section{Methods}

\section{Study Design}

A cohort of surgical patients was created for the observational multicentre PERISCOPE study. Sixty-three European hospitals (see appendix) recruited patients during continuous 7-day periods, choosing a convenient date to begin data collection between 2 May and 15 August 2011. Follow-up ended in November 2011. The participating hospitals constituted a convenience sample of volunteer centres found through the European Society of Anaesthesiology (ESA); candidates were approached directly by national study coordinators. The study was registered at ClinicalTrials.gov (identifier, NCT01346709).

\section{PERISCOPE Cohort Inclusion and Exclusion Criteria}

Consecutive patients undergoing nonobstetric in-hospital elective or emergent surgery under general (including combined general anaesthesia) or regional (neuroaxial or plexus) anaesthesia were recruited.

Exclusion criteria were age under 18 years; obstetric procedures or any procedure during pregnancy; procedures in which only local or peripheral nerve anaesthesia would be used; procedures outside an operating theatre; procedures related to a previous postoperative complication; organ transplantation; patients with preoperatively intubated trachea; and outpatient procedures, defined as those requiring a hospital stay of less than 24 hours. 


\section{Ethical Considerations}

Ethics requirements differed in the 21 countries, but formal approval from a research ethics review board was applied for and given in each: the locally responsible investigator applied for and obtained approval from the ethics committee of each participating hospital. Written informed consent was obtained from each patient.

\section{Organisation, Data Collection and Quality Assurance}

The research team consisted of a steering committee and nationally and locally responsible investigators, who were all anaesthesiologists. Data collectors, who did not modify a centre's customary management of patients, used a structured questionnaire to record the following information: administrative data (dates of surgery and discharge; status alive or dead - at discharge), general information (sex, birth date, height, and weight), preoperative variables (oxyhaemoglobin saturation measured by pulse oximetry $\left[\mathrm{SpO}_{2}\right]$ breathing air in supine position after 1 minute resting breathing air, or in patients on oxygen, $\mathrm{SpO}_{2}$ after 10 minutes without oxygen; respiratory symptoms based on a simplified version of the Medical Research Council questionnaire; ${ }^{18}$ respiratory infection in the last month; haemoglobin concentration; cough test; chronic pulmonary disease; smoking status; and the American Society of Anesthesiologists [ASA] class), and intraoperative variables (surgical incision, surgical duration in hours, type of surgery [scheduled or emergent], description of procedure, surgical specialty and anaesthetic technique). Definitions of all variables are in the online supplement (Supplementary Table 1). 
The data collectors also sought all PPCs by searching medical records daily to find relevant events until hospital discharge; information on PRF was thus recorded as this complication developed throughout the hospital stay. Data were collected on paper forms and then transferred anonymously to secure online case records (OpenClinica, Boston, MA). This electronic system incorporated quality control algorithms to validate online data entry and identify missing data. An off-site data manager checked entries to confirm completeness and asked the local team contact to provide additional information if necessary. An expert on the International Classification of Diseases, Ninth Revision, Clinical Modification, coded all diagnoses and procedures at the end of the collection period.

\section{Outcomes}

The primary outcome of interest for this secondary analysis was PRF defined as new-onset hypoxaemia appearing within 5 postoperative days at 3 levels of severity: mild $\left(\mathrm{PaO}_{2}<60 \mathrm{mmHg}\right.$ or $\mathrm{SpO}_{2}<90 \%$ in room air but responding to mask/nasal supplemental oxygen); moderate (necessitating noninvasive or invasive mechanical ventilation to treat a $\mathrm{PaO}_{2}<60 \mathrm{mmHg}$ or $\mathrm{SpO}_{2}<90 \%$ ); or severe (requiring invasive mechanical ventilation to manage a $\mathrm{PaO}_{2} / \mathrm{FiO}_{2}<200 \mathrm{mmHg}$ regardless the level of positive endexpiratory pressure [PEEP]). Hypoventilation due to residual effects of anaesthetics or opiates and heart failure were ruled out in all cases.

Secondary outcomes of interest were postoperative intensive care unit (ICU) admission, postoperative length of stay (LOS), and in-hospital mortality. 


\section{Statistical Analysis}

The size of the PERISCOPE cohort had been calculated to provide at least 10 events per variable we expected to enter the logistic regression model. ${ }^{19}$ It was estimated that the 63 PERISCOPE centres would be able to collect

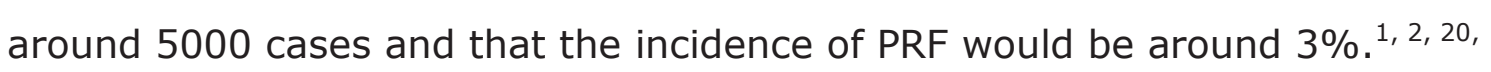
${ }^{21}$ Recording at least 150 PRF events would allow around 15 predictor variables to be entered into logistic regression. Demographic and clinical characteristics are expressed in percentages and medians and interquartile ranges (IQR).

Potential PRF predictors were selected according to the investigators' consensus on measurable preoperative variables or the results of previous studies. ${ }^{22}$. Independent continuous variables (age, $\mathrm{SpO}_{2}$, and duration of surgery) were grouped into categories based on the investigators' understanding of relevant clinical cut points.

Unadjusted associations between all categorical variables and PRF were evaluated with the chi-square test or the Fisher exact test, as appropriate. Bivariate odds ratios (ORs) and 95\% confidence intervals (CIs) were also estimated. The possibility of colinearity between categorical variables was tested with the Cramer V test (nominal variables) or Kendall's tau-b (ordinal variables).

The logistic regression model was constructed using a backward stepwise selection procedure in which the presence of PRF was the dependent variable. Independent predictors were entered into the model if a significant association $(P<0.05)$ was identified on bivariate analysis and the correlation 
coefficient between them (colinearity) was less than 0.25 . Potential predictors were removed if this exclusion did not result in a significant change in the log-likelihood ratio test. The cutoff for variable removal was set at a significance level of 0.05 . Adjusted ORs and $95 \%$ CIs were also calculated.

To avoid overfitting and obtain reliable internal validation of the subset of factors, we used a bootstrap method, ${ }^{23}$ deriving 1000 computer-generated samples by random selection with replacement, each including the same number of patients. Within each bootstrap sample, the $\beta$ coefficient was calculated using all selected independent variables. The robustness of the model and, thus, the reliability of predictor variables in the final regression model were estimated by the $95 \%$ CI of the $\beta$ coefficient derived from the bootstrap samples.

A simplified predictive risk score for clinical use was then calculated by multiplying each $\beta$ coefficient (corrected after bootstrapping) by 10 and rounding to the nearest integer. The integers were added together to produce an overall PRF risk score for each patient. To evaluate the ability of the score to predict increasing PRF risk, we used the minimum description length principle ${ }^{24}$ to divide the sample into 3 risk levels, each with a similar number of patients. The logistic regression model's calibration was then assessed by the Hosmer-Lemeshow goodness-of-fit statistic and by plotting the actual frequency of PRF in each of the 3 risk levels against the predicted probability of PRF in that risk group.

To assess the ability of the simplified PRF risk score to discriminate between patients with and without PRF we used the $c$-statistic, which was also displayed graphically as the area under the receiver operating characteristic 
curve. Additionally, to check the performance of the model if it were used without information for any single factor such as $\mathrm{SpO}_{2}$, which might not be recorded in all centres, we also checked the discriminative performance by calculating the c-statistics and calibration statistics for alternative 6-factor models.

The Mann-Whitney $U$ test was used to compare postoperative LOS between patients with and without PRF. An actuarial life table was constructed to assess in-hospital mortality after development of mild, moderate, or severe PRF. The Wilcoxon-Gehan test was used to compare overall survival curves. Statistical analyses were performed using the SPSS software package (version 20.0; IBM Corp., Armonk, NY). Bootstrapping was performed using R, version 3.0.2 (R Project for Statistical Computing). 


\section{Results}

Of 5859 initially eligible patients, 5384 (91.9\%) were included in the final analysis (see Figure 1). The characteristics of patients and procedures are detailed in Table 1.

PRF developed in 224 patients (4.2\% of the cohort) and was classified as mild in $155(2.9 \%)$, moderate in $43(0.8 \%)$, and severe in $26(0.5 \%)$. The time between surgery and the onset of PRF was a median of 0.5 days (IQR, 1 day). In $54.9 \%$ of the patients with PRF, symptoms began within 24 hours; in $94.6 \%$ onset was within 3 days.

\section{PRF, ICU Stay, Postoperative LOS, and Mortality}

ICU admission was required in $181(80.8 \%)$ of the patients who developed PRF and in $318(6.2 \%)$ of the patients who did not. The ICU stay was significantly longer in patients who developed PRF $(P<0.001)$; these patients were in the unit a median of 44 (72.5) hours whereas the median stay for patients without PRF was 22 (34) hours.

The median in-hospital postoperative stay was also longer in patients with PRF (9 [9] days) than in those without PRF (4 [5] days) $(P<0.001)$. Fortysix patients died in the hospital; 23 of them had PRF (10.3\% of the 224 patients with PRF) and 23 did not ( $0.44 \%$ of the 5160 without PRF) $(P<0.001)$. Figure 2 shows survival curves for in-hospital mortality according to PRF severity. Differences in hospital mortality between PRF severity levels were statistically significant $(P<0.001)$. 


\section{Risk Factors and PRF Score}

The independent variables entered into logistic regression are shown in Table 2, along with variables that were not significant on bivariate analysis or that were significant but rejected because of high colinearity with other variables. Multivariable logistic regression selected 7 independent predictors of PRF: 4 were related to the patient's presurgical health status (low preoperative $\mathrm{SpO}_{2}$ in air, respiratory symptoms, heart failure, and chronic liver disease) and 3 were procedure-related (open thoracic or abdominal surgery, duration, and emergency surgery). All were retained in more than $95 \%$ of the bootstrap subsamples. Table 3 shows the ORs for these predictors. The 7-variable regression model had good discrimination ( $c$ statistic, 0.82) and calibration (Hosmer-Lemeshow $P=0.253$ ). The area under the receiver operating characteristic curve (c-statistic) and calibration plot are presented in Figure 3. Supplementary Table 2 shows the statistics reflecting the performance of the model without inclusion of preoperative $\mathrm{SpO}_{2}$ or any other single factor; the $c$-statistic fell to 0.81 for that model and all other alternative 6-variable models created by removing one of the factors.

The incidence of PRF increased significantly between risk levels (low, <12; intermediate; $12-22 ;$ and high, $\geq 23$ points). The incidences (95\% CIs) were $1.1 \%(0.7 \%-1.5 \%), 4.6 \%(3.4 \%-5.6 \%)$ and $18.8 \%(15.8 \%-21.8 \%)$, respectively, for each level. Table 4 shows sensitivity, specificity and other statistics assessing the predictive utility of the cutoffs for moderate risk ( $\geq 12$ points) and high risk ( $\geq 23$ points). 


\section{Discussion}

The incidence of PRF in this prospective, multicentre surgical cohort receiving general or regional anaesthesia was $4.2 \%$, and risk was predicted by a score based on 7 easily recorded predictors. The PERISCOPE-PRF score performed well, as it was able to identify $82 \%$ of the patients who would develop PRF (as shown by the $c$-statistic of 0.82 ), and it was able to distinguish 3 levels of risk. Calibration measures showed good agreement between the predicted and observed values within the risk levels; bootstrapping confirmed the stability of the dataset and all 7 predictors were retained after the procedure. PRF significantly increased the ICU admission rate, postoperative LOS, and in-hospital mortality.

Several studies of risk have defined a composite PPC as the primary outcome. $2,22,25,26$ The complications most often included are respiratory infection, bronchospasm, PRF, atelectasis, and pleural effusion among others. While such an approach to risk modelling is useful for guiding preoperative management and vigilance, clinicians are aware that the pathogenesis and clinical impact of each component in the composite is substantially different. We therefore designed the present study to determine whether the PERISCOPE model, also designed to predict a composite, could be used to predict only PRF.

Most previous studies of PRF defined this complication as the need for more than 48 hours of mechanical ventilation or unplanned reintubation, $1,3,5,7,11$ which would only identify the most severe forms of PRF. The predictive scores for PRF developed in these studies showed $c$-statistics ranging from $0.79^{11}$ to $0.89^{3}$. The $c$-statistic of 0.82 for the PERISCOPE-PRF score fell 
within this range and is consistent with those earlier findings in spite of differences in definitions or design.

The incidence of PRF in this cohort (4.2\%) was higher than previous rates, which ranged from $2.6 \%$ to $3.4 \%{ }^{1,8,20}$ There are important methodological, population and outcome definition differences between our study and the earlier ones that can account for the higher rate. Our definition of PRF specified that new-onset hypoxaemia of noncardiac cause must have appeared within 5 postoperative days, marked objectively by a level of $\mathrm{SpO}_{2}<90 \%$ breathing air, which corresponds approximately to a ratio of $\mathrm{PaO}_{2} / \mathrm{FIO}_{2}<300$. There is no consensus about the postoperative period within which a PPC can be considered attributable to surgery. ${ }^{8}$ Several studies analysed PRF developing within 30 days, ${ }^{1,3,11}$ whereas others limited the time frame to 3 to 7 days. ${ }^{4-7}$ We chose a 5-day period so that the complication and the surgical-anaesthetic events would be clearly linked, thereby excluding $8.9 \%$ of the PERISCOPE patients who later developed this complication. Although we included patients without previous lung injury and lacked information to calculate the $\mathrm{PaO}_{2} / \mathrm{FIO}_{2}$ ratio for all patients, we did classify PRF in 3 levels of severity, in a way that was similar to the recent ARDS classification. ${ }^{16}$ Our stratification was based on the presence of hypoxaemia and the kind of respiratory support required to manage it (conventional oxygen therapy and noninvasive or invasive mechanical ventilation regardless of PEEP level), a classification consistent with current clinical management of PRF. Up to $74 \%$ of these patients can be managed with noninvasive ventilation, ${ }^{27}$ which several studies have found very effective for treating even severe levels of hypoxaemia. ${ }^{28-31}$ Recently, Kor et $a l^{4}$ found a $2.6 \%$ incidence of ALI in patients undergoing 
high-risk surgery using a similar definition of impaired oxygen exchange $\left(\mathrm{PaO}_{2} / \mathrm{FIO}_{2}<300\right)$, but their definition required the presence of pulmonary infiltrates as well. It is likely that the higher PRF incidence in our study was due to the fact that the measurable criterion was arterial oxygenation $\left(\mathrm{SpO}_{2}\right)$. The incidence of severe PRF in our study $\left(\mathrm{PaO}_{2} / \mathrm{FIO}_{2}<200\right.$ regardless of PEEP level) was $0.5 \%$, similar to previous studies. ${ }^{6}$ However, because of the multicentre nature of our study, we cannot rule out that local clinical practices might have led to differences in the distribution of PRF severity. Practices might even have contributed to preventing the development of PRF, or variations in resources might have led to higher rates of rescue failure ${ }^{32}$ in some centres. However, we think it is important for the clinician to note that all levels of postoperative hypoxaemia severity had an impact on mortality in this cohort (Figure 2), a finding which confirms that PRF prediction overall is of great importance.

Four of the 7 predictors of PRF risk we identified were related to the patient's health status and these factors accounted for $57 \%$ of the total risk. To our knowledge, this is the first study reporting that low preoperative $\mathrm{SpO}_{2}$ breathing air and even a single respiratory symptom are strongly associated with risk for PRF, although slight oxygen desaturation $\left(\mathrm{SpO}_{2} \leq 95 \%\right)$ has been found to be an independent predictor of a composite PPC outcome. ${ }^{2}$ Additionally, clinical prediction using this objective variable is even more precise when 3 levels of $\mathrm{SpO}_{2}(>95 \%, \leq 95 \%$, and $\leq 90 \%$ ) are considered. ${ }^{2}$ In other clinical settings, a low $\mathrm{SpO}_{2}$ is emerging as a good predictor of outcome. ${ }^{33,34}$ The incidence of $\mathrm{SpO}_{2} \leq 95 \%$ in our surgical cohort (18.8\%) was much higher than the incidence of $6.3 \%$ in a recent population-based study. ${ }^{35}$ We interpret this as a sign that a surgical 
population will tend towards impaired cardio-respiratory function. Exclusion of $\mathrm{SpO}_{2}$ from the score when this measurement is not available (for example, in clinical settings where phone screening is used), reduces its performance. Calibration suffers in particular, meaning that the model without $\mathrm{SpO}_{2}$, might not accurately assess level of risk. (See supplementary Table 2.) We therefore think that routine measurement of preoperative $\mathrm{SpO}_{2}$ should be encouraged and that it will probably prove to be a robust predictor of poor postoperative outcome.

Preoperative heart failure is a well recognised risk factor for the development of PPCs. ${ }^{1,5,22}$ In our study, we analysed 3 levels of heart failure according to the NYHA classification, finding that PRF risk increased with severity. We also identified chronic liver disease as a predictor of PRF. Chronic liver disease has been linked to a poor postoperative prognosis overall. ${ }^{36}$ One retrospective study found an association between liver disease and unanticipated early postoperative tracheal intubation after nonemergent noncardiac surgery, ${ }^{5}$ and a retrospective study identified an $8 \%$ rate of ventilatory dependence (postoperative mechanical ventilation $>24$ hours or unplanned intubation) and a similar rate for pneumonia in 733 cirrhotic patients undergoing any surgical procedure. ${ }^{37}$ However, chronic liver disease encompasses a wide spectrum of disorders ranging from fatty liver disease to cirrhosis. No study has sought to define a relationship between the different kinds of liver disease and PRF or other PPCs to date. We did not record different types of liver disease in our study, but the strong association we found between this factor and PRF suggests that more accurate records should be used in future studies. 
The 3 remaining independent risk factors were associated with surgical procedure. In most previous studies surgical incision, duration of surgery, and emergency status have been proposed as predictors of PPCs. ${ }^{22}$ However, in the PRF score we present, we further distinguished open and closed surgery because closed surgery has been associated with less postoperative pneumonia, PRF and mortality, ${ }^{38}$ consistent with our finding that closed abdominal surgery approximately halved the risk for PRF and closed thoracic surgery reduced risk 4-fold.

Thus, although the identified risk factors differ slightly from study to study, we see commonalities. Patient-associated risk factors, which depend fundamentally on comorbidity, and procedure-associated risk factors are very similar across the studies. High risk and emergent surgery were identified as risk factors in most of the studies. 1, 3, 4, 7

A strength of our study is that all variables were chosen and defined a priori and cases were identified prospectively by daily searches of records. Moreover, we included patients undergoing a broad spectrum of surgeries rather than limiting the study to an specific patient population or procedure. ${ }^{39}$ This approach sought to enhance the reliability of the findings so that they would be generalisable to the real world of anaesthetics and surgery.

A limitation of this study is that postoperative follow-up ended at hospital discharge. Second, the cohort was recruited by volunteer hospitals that did not cover the entire territory of Europe. Third, possible intraoperative events that might be related to PRF, such as respiratory complications, blood loss or ventilatory management, were not taken into account. Fourth, 
the present study reports internal validation of the score; external validation remains to be performed.

Identifying patients at high risk for developing PRF is of great value in clinical making-decision about perioperative measures to be applied. Among the measures that have been shown to reduce the incidence of PRF, we mention preoperative optimisation of some health conditions such as smoking and alcohol cessation, ${ }^{40,41}$ intraoperative ventilatory management, ${ }^{42-44}$ and postoperative analgesia and physiotherapy. ${ }^{45,46}$ Although strategies to reduce PRF risk have also been shown to reduce health costs, ${ }^{47-50}$ randomised trials to test the efficacy of preventive measures are still lacking. The PERISCOPE-PRF score developed in this study can be useful for classifying patients systematically in such trials. In conclusion, PRF is a frequent complication and is associated with a poor prognosis, but the PERISCOPE-PRF score is likely to help identify surgical patients at risk so that stricter measures to prevent this life-threatening complication can be considered.

\section{Acknowledgements}

The PERISCOPE study was funded and supported through the ESA's Clinical Trials Network. The off-site data manager who checked entries for completeness was an ESA staff member. The ESA also supported organisational meetings, communication between centres, and manuscript editing for English language expression. The authors thank Brigitte Leva, of the ESA, for her assistance as data manager, and Mary Ellen Kerans, for 
manuscript editing and advice on the English usage in some versions of the manuscript.

All authors declare no conflict of interest. 


\section{Figure legends}

Figure 1. Recruitment flowchart.

Figure 2. Plot of survival predicted by the risk score against overall (actuarial) survival after development of mild, moderate, or severe postoperative respiratory failure (PRF).

Figure 3. The risk model's performance: $A$, Receiver operating characteristics curve (to show discrimination); B, Agreement between observed frequency and predicted probability at 3 levels of risk (to assess calibration). Triangles represent the values for risk groups (patients whose scores reflected low, intermediate, or high risk). AUC $=$ area under curve (c-statistic); $\mathrm{H}-\mathrm{L} \chi^{2}=$ Hosmer-Lemeshow chi-square goodness-of-fit test. 


\section{References}

1 Arozullah AM, Daley J, Henderson WG and Khuri SF. Multifactorial risk index for predicting postoperative respiratory failure in men after major noncardiac surgery. The National Veterans Administration Surgical Quality Improvement Program. Ann Surg 2000; 232: 242-253.

2 Canet J, Gallart L, Gomar C et al. Prediction of postoperative pulmonary complications in a population-based surgical cohort. Anesthesiology 2010; 113: 1338-1350.

3 Gupta H, Gupta PK, Fang X et al. Development and validation of a risk calculator predicting postoperative respiratory failure. Chest 2011; 140: 1207-1215.

4 Kor DJ, Warner DO, Alsara A et al. Derivation and diagnostic accuracy of the surgical lung injury prediction model. Anesthesiology 2011; 115: 117-128.

5 Ramachandran SK, Nafiu OO, Ghaferi A, Tremper KK, Shanks A and Kheterpal S. Independent predictors and outcomes of unanticipated early postoperative tracheal intubation after nonemergent, noncardiac surgery. Anesthesiology 2011; 115: 44-53.

6 Blum JM, Stentz MJ, Dechert $\mathrm{R}$ et al. Preoperative and intraoperative predictors of postoperative acute respiratory distress syndrome in a general surgical population. Anesthesiology 2013; 118: 19-29. 
7 Brueckmann B, Villa-Uribe JL, Bateman BT et al. Development and validation of a score for prediction of postoperative respiratory complications. Anesthesiology 2013; 118: 12761285.

8 Canet J and Gallart L. Postoperative respiratory failure: pathogenesis, prediction, and prevention. Curr Opin Crit Care 2014; 20: 56-62.

9 Roussos C and Koutsoukou A. Respiratory failure. Eur Respir J Supp/ 2003; 47: 3s-14s.

10 Trillo-Alvarez C, Cartin-Ceba R, Kor DJ et al. Acute lung injury prediction score: derivation and validation in a population-based sample. Eur Respir J 2011; 37: 604-609.

11 Hua M, Brady JE and Li G. A scoring system to predict unplanned intubation in patients having undergone major surgical procedures. Anesth Analg 2012; 115: 88-94.

12 Utter GH, Cuny J, Sama P et al. Detection of postoperative respiratory failure: how predictive is the Agency for Healthcare Research and Quality's Patient Safety Indicator? J Am Coll Surg 2010; 211: 347-354.

13 Pelosi P and Gama de Abreu M. Lung injury prediction models to improve perioperative management: let's hit the bull's-eye! Anesthesiology 2011; 115: 10-11.

14 Koch CG, Li L, Hixson E, Tang A, Phillips S and Henderson JM. What are the real rates of postoperative complications: 
elucidating inconsistencies between administrative and clinical data sources. J Am Coll Surg 2012; 214: 798-805.

15 Young $A$ and Ramachandran SK. Clinical prediction of postoperative respiratory failure. Anesthesiology 2013; 118: 1247-1249.

16 Ranieri VM, Rubenfeld GD, Thompson BT et al. Acute respiratory distress syndrome: the Berlin Definition. JAMA 2012; 307: 25262533.

17 Canet J, Hardman J, Sabate S et al. PERISCOPE study: predicting post-operative pulmonary complications in Europe. Eur $J$ Anaesthesiol 2011; 28: 459-461.

18 Cotes JE. Medical Research Council Questionnaire on Respiratory Symptoms (1986). Lancet 1987; 2: 1028.

19 Peduzzi P, Concato J, Kemper E, Holford TR and Feinstein AR. A simulation study of the number of events per variable in logistic regression analysis. J Clin Epidemiol 1996; 49: 1373-1379.

20 Johnson RG, Arozullah AM, Neumayer L, Henderson WG, Hosokawa $\mathrm{P}$ and Khuri SF. Multivariable predictors of postoperative respiratory failure after general and vascular surgery: results from the patient safety in surgery study. J Am Coll Surg 2007; 204: 1188-1198.

21 Money SR, Rice K, Crockett D et al. Risk of respiratory failure after repair of thoracoabdominal aortic aneurysms. Am J Surg 1994; 168: 152-155. 
22 Smetana GW, Lawrence VA and Cornell JE. Preoperative pulmonary risk stratification for noncardiothoracic surgery: Systematic review for the American College of Physicians. Ann Intern Med 2006; 144: 581-595.

23 Steyerberg EW, Harrell FE, Jr., Borsboom GJ, Eijkemans MJ, Vergouwe $Y$ and Habbema JD. Internal validation of predictive models: efficiency of some procedures for logistic regression analysis. J Clin Epidemiol 2001; 54: 774-781.

24 Liu $\mathrm{H}$, Hussain F, Tan $\mathrm{CL}$ and Dash M. Discretization: An Enabling Technique. Data Min Knowl Discov 2002; 6: 393-423.

25 Mitchell CK, Smoger SH, Pfeifer MP et al. Multivariate analysis of factors associated with postoperative pulmonary complications following general elective surgery. Arch Surg 1998; 133: 194198.

26 McAlister FA, Bertsch K, Man J, Bradley J and Jacka M. Incidence of and risk factors for pulmonary complications after nonthoracic surgery. Am J Respir Crit Care Med 2005; 171: 514-517.

27 Redondo Calvo FJ, Madrazo M, Gilsanz F, Una R, Villazala R and Bernal G. Helmet noninvasive mechanical ventilation in patients with acute postoperative respiratory failure. Respir Care 2012; 57: $743-752$.

28 Squadrone V, Coha M, Cerutti E et al. Continuous positive airway pressure for treatment of postoperative hypoxemia: a randomized controlled trial. JAMA 2005; 293: 589-595. 
29 Michelet $\mathrm{P}, \mathrm{D}^{\prime}$ 'Journo $\mathrm{XB}$, Seinaye F, Forel JM, Papazian $\mathrm{L}$ and Thomas P. Non-invasive ventilation for treatment of postoperative respiratory failure after oesophagectomy. $\mathrm{Br} \mathrm{J}$ Surg 2009; 96: 54-60.

30 Jaber S, Michelet $\mathrm{P}$ and Chanques G. Role of non-invasive ventilation (NIV) in the perioperative period. Best Pract Res Clin Anaesthesiol 2010; 24: 253-265.

31 Glossop AJ, Shephard N, Bryden DC and Mills GH. Non-invasive ventilation for weaning, avoiding reintubation after extubation and in the postoperative period: a meta-analysis. $\mathrm{Br} \mathrm{J}$ Anaesth 2012; 109: 305-314.

32 Wakeam E, Hevelone ND, Maine R et al. Failure to rescue in safety-net hospitals: availability of hospital resources and differences in performance. JAMA Surg 2014; 149: 229-235.

33 Millman AL, Payne B, Qu Z et al. Oxygen saturation as a predictor of adverse maternal outcomes in women with preeclampsia. J Obstet Gynaecol Can 2011; 33: 705-714.

34 Seymour CW, Kahn JM, Cooke CR, Watkins TR, Heckbert SR and Rea TD. Prediction of critical illness during out-of-hospital emergency care. JAMA 2010; 304: 747-754.

35 Vold ML, Aasebo U, Hjalmarsen A and Melbye H. Predictors of oxygen saturation $</=95 \%$ in a cross-sectional population based survey. Respir Med 2012; 106: 1551-1558. 
36 Pandey CK, Karna ST, Pandey VK, Tandon M, Singhal A and Mangla V. Perioperative risk factors in patients with liver disease undergoing non-hepatic surgery. World J Gastrointest Surg $2012 ; 4: 267-274$.

37 Ziser A, Plevak DJ, Wiesner RH, Rakela J, Offord KP and Brown DL. Morbidity and mortality in cirrhotic patients undergoing anesthesia and surgery. Anesthesiology 1999; 90: 42-53.

38 Masoomi H, Buchberg B, Nguyen B, Tung V, Stamos MJ and Mills S. Outcomes of laparoscopic versus open colectomy in elective surgery for diverticulitis. World J Surg 2011; 35: 2143-2148.

39 Canet J and Gallart L. Predicting postoperative pulmonary complications in the general population. Curr Opin Anaesthesiol 2013; 26: 107-115.

40 Musallam KM, Rosendaal FR, Zaatari G et al. Smoking and the risk of mortality and vascular and respiratory events in patients undergoing major surgery. JAMA Surg 2013; 148: 755-762.

41 Tonnesen $\mathrm{H}$, Nielsen PR, Lauritzen JB and Moller AM. Smoking and alcohol intervention before surgery: evidence for best practice. Br J Anaesth 2009; 102: 297-306.

42 Severgnini P, Selmo G, Lanza C et al. Protective mechanical ventilation during general anesthesia for open abdominal surgery improves postoperative pulmonary function. Anesthesiology 2013; 118: 1307-1321. 
43 Futier $\mathrm{E}$, Constantin JM, Paugam-Burtz $\mathrm{C}$ et al. A trial of intraoperative low-tidal-volume ventilation in abdominal surgery. N Engl J Med 2013; 369: 428-437.

44 Hemmes SN, Gama de Abreu M, Pelosi P and Schultz MJ. High versus low positive end-expiratory pressure during general anaesthesia for open abdominal surgery (PROVHILO trial): a multicentre randomised controlled trial. Lancet 2014; 384: 495503.

45 Makhabah DN, Martino F and Ambrosino N. Peri-operative physiotherapy. Multidiscip Respir Med 2013; 8: 4.

46 Cassidy MR, Rosenkranz P, McCabe K, Rosen JE and McAneny D. I COUGH: Reducing Postoperative Pulmonary Complications With a Multidisciplinary Patient Care Program. JAMA Surg 2013; 148: 740-745.

47 Fuller RL, McCullough EC, Bao MZ and Averill RF. Estimating the costs of potentially preventable hospital acquired complications. Health Care Financ Rev 2009; 30: 17-32.

48 Carey K, Stefos T, Shibei Z, Borzecki AM and Rosen AK. Excess costs attributable to postoperative complications. Med Care Res Rev 2011; 68: 490-503.

49 Sasaki N, Meyer MJ and Eikermann M. Postoperative respiratory muscle dysfunction: pathophysiology and preventive strategies. Anesthesiology 2013; 118: 961-978. 
50 Sabate S, Mazo V and Canet J. Predicting postoperative pulmonary complications: implications for outcomes and costs. Curr Opin Anaesthesiol 2014; 27: 201-209. 


\section{Appendix}

\section{List of Participating Centres and Contributors to the PERISCOPE Cohort Study}

\section{Chief investigator}

Jaume Canet, Hospital Universitari Germans Trias i Pujol, Barcelona, Spain

\section{Steering Committee Members}

Jaume Canet, Spain

Sergi Sabaté, Spain

Olivier Langeron, France

Marcelo Gama de Abreu, Germany

Lluís Gallart, Spain

F. Javier Belda, Spain

Paolo Pelosi, Italy

Andreas Hoeft, Germany

Valentin Mazo, Spain

\section{Off-site Data Management}

Brigitte Leva, European Society of Anaesthesiology aisbl (Brussels), Belgium
Albania
1. University Hospital centre "Mother Theresa" (Tirana): Jonela Burimi, Toma Halefi, Aleksander Hoxha*, Kliti Pilika, Imelda Selmani

\section{Belgium}

1. Cliniques Universitaires Saint Luc A.S.B.L Université Catholique de Louvain (Brussels): Véronique Daout, Caroline Gauthier, David Kahn, Mona Momeni*, Christine Watremez

\section{Bosnia and Herzegovina}

1. Clinical Centre University Sarajevo "Heart Centre" (Sarajevo): Slavenka Straus*

2. General Hospital "Prim.dr Abdulah Nakas"(Sarajevo): Dejana Djonovic-manovic, Marina Juros-Zovko*

\section{Croatia}

1. University Hospital Rijeka (Rijka): Helga Komen-Ušljebrka*, Vlasta Orlić, Ivana Stuck

\section{Czech Republic}


1. Faculty Hospital Brno (Brno): Lenka Baláková, Martina Kosinová, Ivo Křikava, Roman Štoudek, Petr Štourač*, Katarina Zadražilová

2. Masaryks hospital Usti nad labem (Usti Nad Labem): Sanober Janvekar*

\section{Estonia}

1. Tartu University Hospital (Tartu): Juri Karjagin, Kadri Rõivassepp, Alar Sõrmus*

\section{France}

1. Hôpital Pitié-Salpêtrière (Paris): Philippe Cuvillon, Cristina Ibáñez-Esteve, Olivier Langeron*, Mathieu Raux, Armelle Nicolas-Robin

\section{Germany}

Klinikum Darmstadt GmbH (Darmstadt): André Winter*

1. Medical Centre of the Johannes Gutenberg University Mainz (Mainz): Malte Brunier, Kristin Engelhard, Rita Laufenberg Feldmann*, Raphaele Lindemann, Susanne Mauff, Anne Sebastiani, Camila Zamperoni

2. University Hospital Bonn (Bonn): Andreas Hoeft*, Florian Kessler, Maria Wittmann

3. University Hospital Carl Gustav Carus - Dresden University of Technonology (Dresden): Thomas Bluth, Marcelo Gama de Abreu*, Andreas Güldner, Thomas Kiss

\section{Hungary}

1. MISEK Kft. (Miskolc): Kristina Bráz, Csilla Ruszkai*

\section{Italy}

1. Azienda Ospedaliera (Padova): Massimo Micaglio, Carlo Ori, Matteo Parotto*, Paolo Persona

2. Azienda Ospedaliera S. Croce e Carle (Cuneo): Coletta Giuseppe*

3. Azienda USL n. 5 di Pisa Ospedale F. Lotti (Pontedera): Paolo Carnesecchi, Denise Lazzeroni, Irene Lorenzi*

4. European Institute of Oncology (Milano): Gianluca Castellani, Daniele Sances*, Gianluca Spano, Stefano Tredici, Dario Vezzoli 
5. Ospedale San Martino (Genova): Iole Brunetti, Anna Di Noto, Angelo Gratarola, Alexandre Molin*, Luca Montagnani, Giulia Pellerano, Paolo Pelosi

6. Ospedale Sant'Orsola - Malpighi (Bologna): Maurizio Fusari*

7. University of Insubria (Varese): Laura Camici, Luca Guzzetti, Fabio Marangoni, Paolo Severgnini*

8. University of Milano, Ospedale San Paolo (Milano): Piero Di Mauro, Francesca Rapido, Concezione Tommasino*

\section{Latvia}

1. Pauls Stradins Clinical University hospital (Riga): Ieva Nemme, Janis Nemme*

\section{Lithuania}

1. Kaunas Medical University Hospital (Kaunas):, Justinas Blieka, Jurgita Borodičienè, Brigita Budrytè, Aurika Karbonskiene*, Inga Kiudulaitè, Eglè Milieškaitè, Renata Rasimavičiūtè, Ugnè Sirevičienè, Ramunè Stašaitytè, Edgaras Ūsas, Giedrè Žarskienè

2. Vilnius University Hospital Santariskiu Clinics (Vilnius): Egle Kontrimaviciute, Jurate Sipylaite*, Gabija Tomkute

\section{Luxembourg}

1. ZithaKlinik(Luxembourg): Petra Bardea, Marco Klop, Marc Koch*

\section{Poland}

1. 10 Wojskowy Szpital Kliniczny z Polikliniką w Bydgoszczy (Bydgoszcz): Dominika Bożiłow, Robert Goch*

\section{Portugal}

1. Hospitais da Universidade de Coimbra, EPE. (Coimbra): João Bonifácio, Sofia Marques, Tânia Teresa dos Santos Ralha*

2. Centro Hospitalar de Lisboa Ocidental (Lisbon): Daniel Alves, Inês Carvalho, Josefina Suzana Da Cruz Parente*, Sara Tomé

3. Hospital Fernando Fonseca (Lisbon): Cristina Carmona*

4. Instituto Português de Oncologia Do Porto (Porto): Miranda Costa*, Maria Lina, Sofia Sierra 


\section{Romania}

1. Emergency Clinical Hospital of Constanta (Constanta): Alina Balcan, Iulia Cindea, Viorel Ionel Gherghina*, Catalin Grasa

2. Emergency County Hospital Clinic of Anaesthesia and Intensive Care (Târgu Mures): Ruxandra Copotoiu, Sanda-Maria Copotoiu*, Judit Kovacs*, Janos Szederjesi, Arthur Theil

3. Emergency Institute of Cardiovascular Diseases Prof Dr C. C. Iliescu (Bucharest): Daniela Filipescu*

\section{Russia}

1. Krasnoyarsk State Medical University (Krasnoyarsk): Alexey Grytsan*, Tatiana Kapkan, Sergey Rostovtsev, Anastasia Yushkova

\section{Spain}

1. Clinica Universidad de Navarra (Pamplona): Ricardo Calderón, Elena Cacho, Carolina Marginet, Pablo Monedero*, Maria José Yepes

2. Consorcio Hospital General Universitario de Valencia (Valencia): Jose Miguel Esparza Miñana, Manuel Granell Gil*, Gabriel Rico Portolés

3. Corporació Sanitària Parc Taulí (Barcelona Sabadell): Alberto Lisi*, Gisela Perez, Nuria Poch

4. Fundacio Althaia (Manresa): Mauricio Roberto Argañaraz Quinteros, Carme Font Bosch, Jordi Torrellardona Llobera*

5. Fundació Puigvert (Barcelona): Sergi Sabaté*, Pilar Sierra

6. Hospital Arnau de Vilanova (Lleida): Mercedes Matute*

7. Hospital Clinic de Barcelona (Barcelona): Amalia Alcon Dominguez*, María José Arguis, Isabel Belda, Enrique Carrero, Jacobo Moreno, Irene Rovira, Marta Ubre, Roberto Castillo, Sílvia Herrero

8. Hospital Clínic Universitari de Valencia (Valencia): Maria Teresa Ballester Luján*, F.Javier Belda, José Carbonell, Geri Gencheva, Andrea Gutierrez, Julio Llorens, Sofia Machado

9. Hospital de Denia (Denia): Francisca Llobell*, Daniel Paz Martin 
10. Hospital del Tajo Aranjuez (Madrid): Francisco Javier García-Miguel*

11. Hospital General de La Palma Breña Alta (La Palma, Canarias): Aníbal Pérez García*

12. Hospital General Universitario Alicante (Alicante): Roque Company*, Aixa Ahamdanech Idrissi, Josefina del Fresno Cañaveras, Jose Alejandro Navarro Martinez ; Estefania Paya Martinez, Ester Sanchez Garcia

13. Hospital San Jorge (Huesca); Jorge Vera Bella*

14. Hospital Sant Pau (Barcelona): Inmaculada India Aldana, J. Manuel Campos, Xavier Pelaez Vaamonde*

15. Hospital Santa Maria (Lleida): Montserrat Torra*

16. Hospital Universitari del Mar 'Parc de Salut Mar (Barcelona): Raquel Arroyo, Juan Carlos Cabrera, Jesús Carazo Cordobes*, Lluís Gallart, Amelia Rojo, Francisco Javier Santiveri

17. Hospital Universitari Germans Trias i Pujol (Badalona): Jaume Canet*, Miriam González, Anabel Jiménez, Yolanda Jiménez, Agnès Martí, Valentin Mazo, Enrique Moret, Monica Rodriguez Nuñez*, Joaquin Velasco

18. Hospital Universitario 12 de Octubre (Madrid): Adriana Calderón, Matide González, Olga González, Ana Hermira Anchuelo*, Eloisa López, Esther Sánchez

19. Hospital Universitario de La Princesa (Móstoles-Madrid): Blanca Aznárez Zango*, Francisco José García Corral, Esperanza Mata Mena, Antonio Planas Roca

20. Hospital Universitario de Móstoles (Madrid): Raquel Fernández Rocío Ayala Soto*, Borja Quintana

21. Hospital Universitario Marques De Valdecilla (Santander): Jose Manuel Rabanal Llevot*, Mónica Mercedes Williams Camus, Alba Palacios Blanco, Angela Largo Ruiz

22. Hospital Universitario Rio Hortgea (Valladolid): Jesus Rico Feijoo*

23. Hospital Universitario Virgen del Rocio (Sevilla): Elvira Castellano Garijo* 
24. Hospital Son Llatzer (Palma de Mallorca): Julio Belmonte Cuenca*, Marcos José Bonet Binimelis, Ivaylo Grigorov, Josep Lluis Aguilar

25. Vall d'Hebron University Hospital (Barcelona): Míriam De Nadal Clanchet, Encarnación Guerrero Viñas, Susana Manrique Muñiz, Víctor Martín Mora, Francisca Munar Bauzà, Sonia Núñez Aguado, Montserrat Olivé Vidal*, María luisa Paños Gozalo, Marcos Sánchez Marín, María Carmen Suescun López

\section{Switzerland}

1. Ospedale Regionale di Lugano (Lugano): Paolo Maino*

\section{Ukraine}

1. St.Katherine Hospital of Cardiology (Odessa): Yevhen Eugene Yevstratov*

\section{Turkey}

1. Medical Faculty of Istanbul, Istanbul University (Istanbul): Semra Kucukgoncu, Nuzhet Mert Sentürk*, Zerrin Sungur Ulke

* Site leader.

PERISCOPE $=$ Prospective Evaluation of a RIsk Score for postoperative pulmonary COmPlications in Europe 
Table 1. Demographic and Clinical Characteristics*

Total No. (\%) of patients

$5384(100)$

Male sex, n (\%)

$2733(50.8)$

Age, median (IQR), y

$58.9(26.1)$

Smoking status, $\mathrm{n}(\%)$

Never smoker

$2833(52.6)$

Former smoker

$1309(24.3)$

Current smoker

$1242(23.1)$

Preoperative $\mathrm{SpO}_{2}$, median (IQR), \%

$97(3)$

Body mass index, median (IQR), $\mathrm{kg} / \mathrm{m}^{2}$

COPD, n (\%)

$538(10.0)$

Respiratory infection in the last month, $\mathrm{n}(\%)$

$298(5.5)$

ASA physical status, $\mathrm{n}(\%)$

1

$1204(22.4)$

2

$2738(50.8)$

3

$1336(24.8)$

4

$106(2.0)$

Emergency surgery, $\mathrm{n}(\%)$

609 (11.3)

Anaesthesia, n (\%)

General and combined †

4125 (76.6) 
Surgical specialty, n (\%)

General and digestive

$1427(26.5)$

Orthopaedic

$1064(19.8)$

Urology

$702(13.0)$

Gynaecology

$452(8.4)$

Neurosurgery

ENT

Vascular

Cardiac

$167(3.1)$

Breast

$161(3.0)$

Thoracic

$145(2.7)$

Other

$400(7.4)$

Duration of surgery, median (IQR), $\mathrm{h}$

Postoperative Preoperative length of stay, median (IQR), d

Postoperative ICU admission, $\mathrm{n}(\%)$

$499(9.3)$

ICU length of stay, median (IQR), $\mathrm{h}$

Postoperative hospital length of stay, median (IQR), d

In-hospital mortality, n (\%)

$46(0.9)$

ASA = American Society of Anesthesiologists; $C O P D=$ chronic obstructive pulmonary disease; $E N T=$ ears nose and throat; ICU = intensive care unit; IQR = interquartile range; $\mathrm{SpO}_{2}=$ oxyhaemoglobin saturation by pulse oximetry breathing air in supine position.

* Data are number of patients unless otherwise indicated. 
† This category included general anaesthesia alone and general anaesthesia combined with regional blockade. 


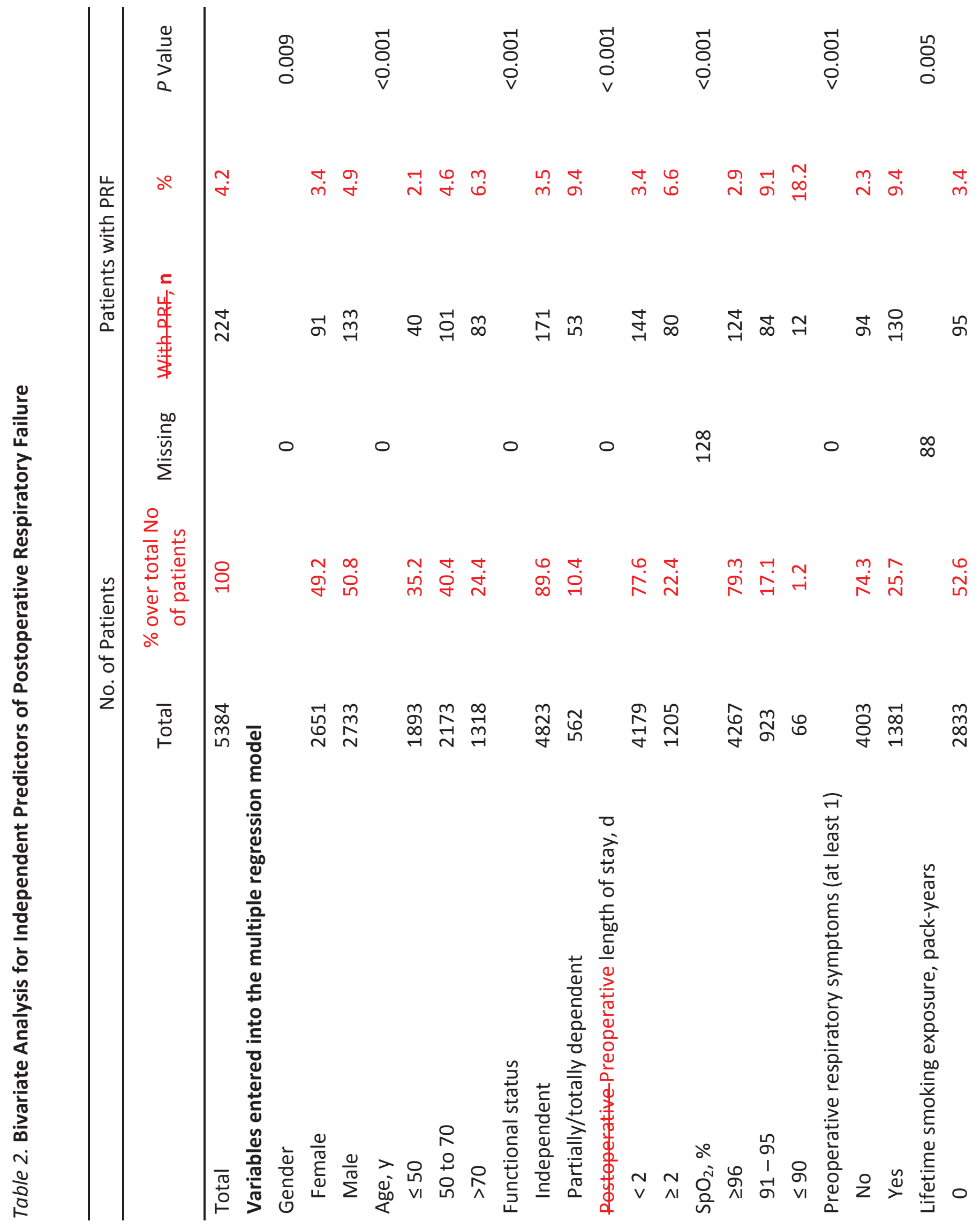


$\begin{array}{llllllll}\overrightarrow{0} & \overrightarrow{0} & \overrightarrow{0} & \overrightarrow{0} & \overrightarrow{0} & \overrightarrow{0} & \overrightarrow{0} \\ \dot{0} & \dot{0} & \dot{0} & \dot{0} & \dot{0} & \dot{v} & \dot{v} & \dot{v}\end{array}$

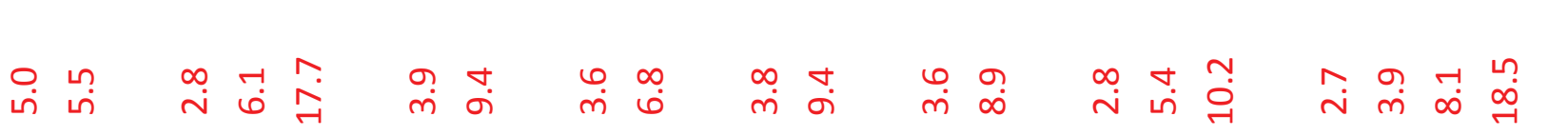

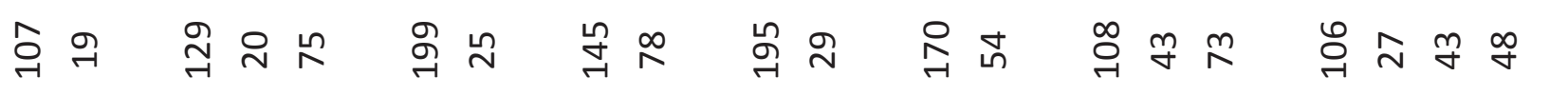

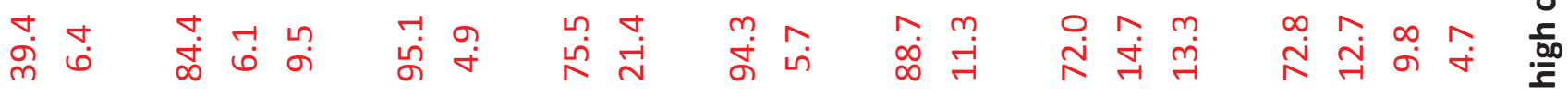

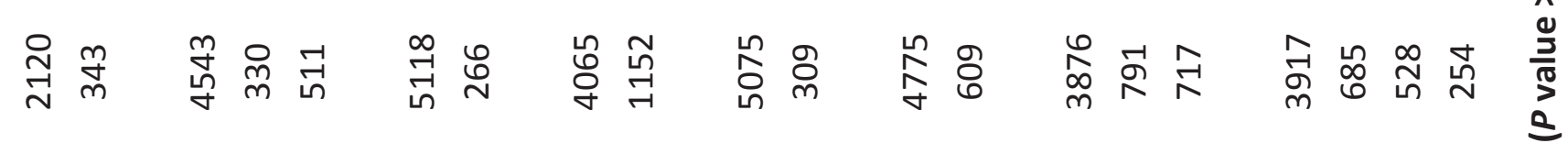

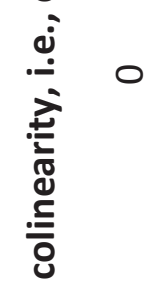

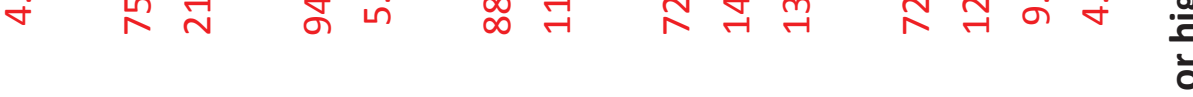

坚

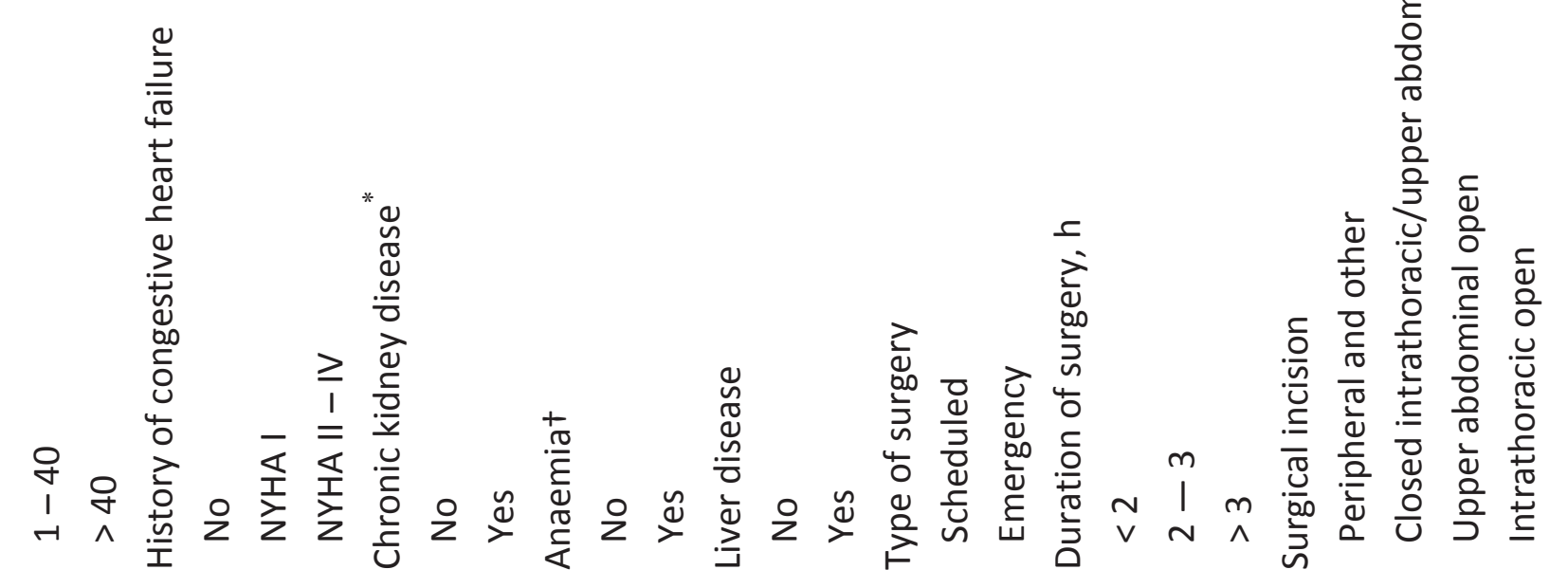

$\frac{\sqrt{0}}{\stackrel{\frac{0}{c}}{\frac{0}{0}}}$ 
量 总

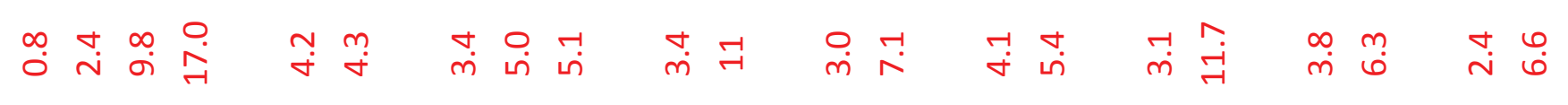

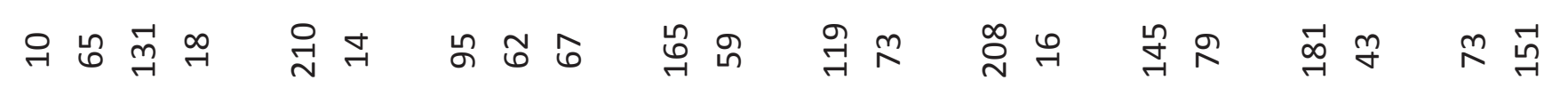

$\circ \circ \circ \frac{m}{7} \circ \circ \circ$

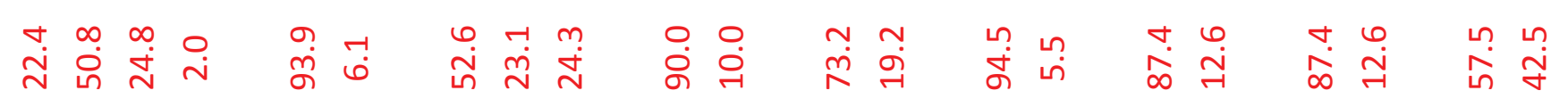

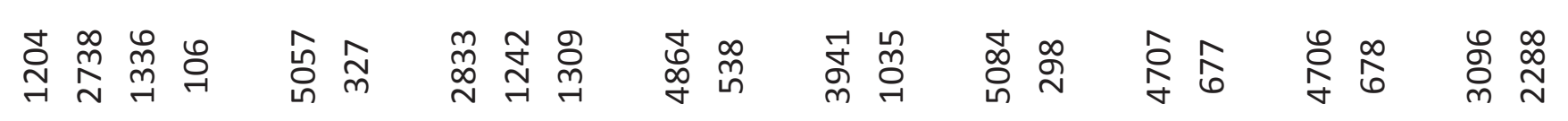

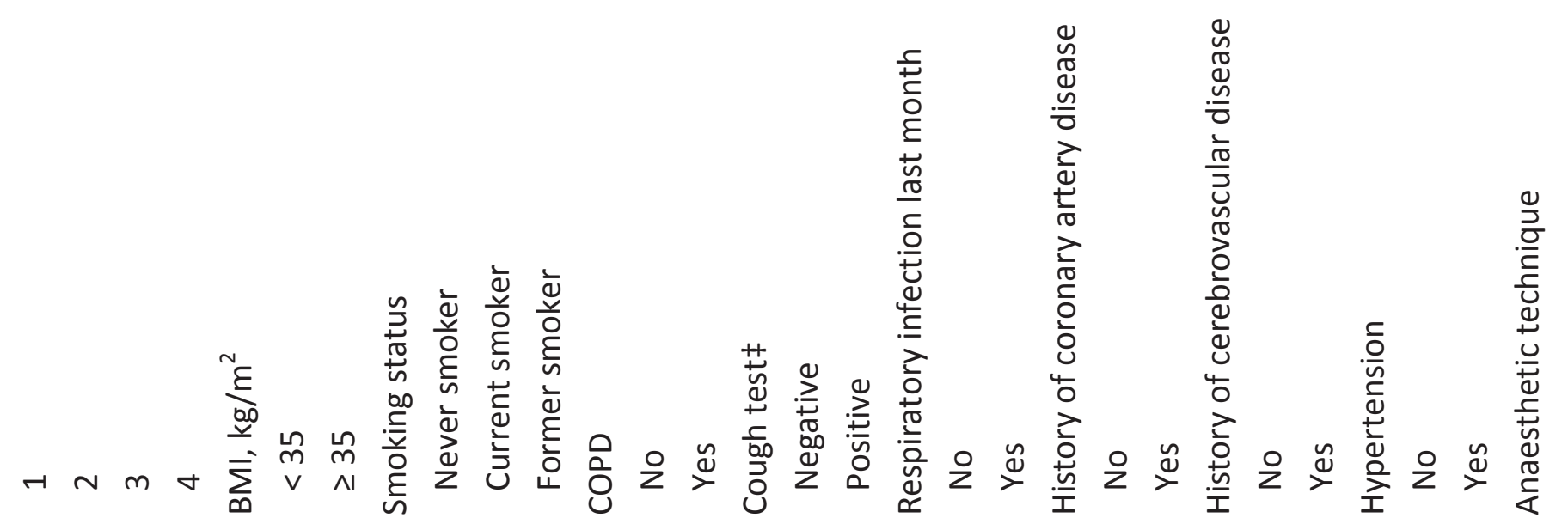




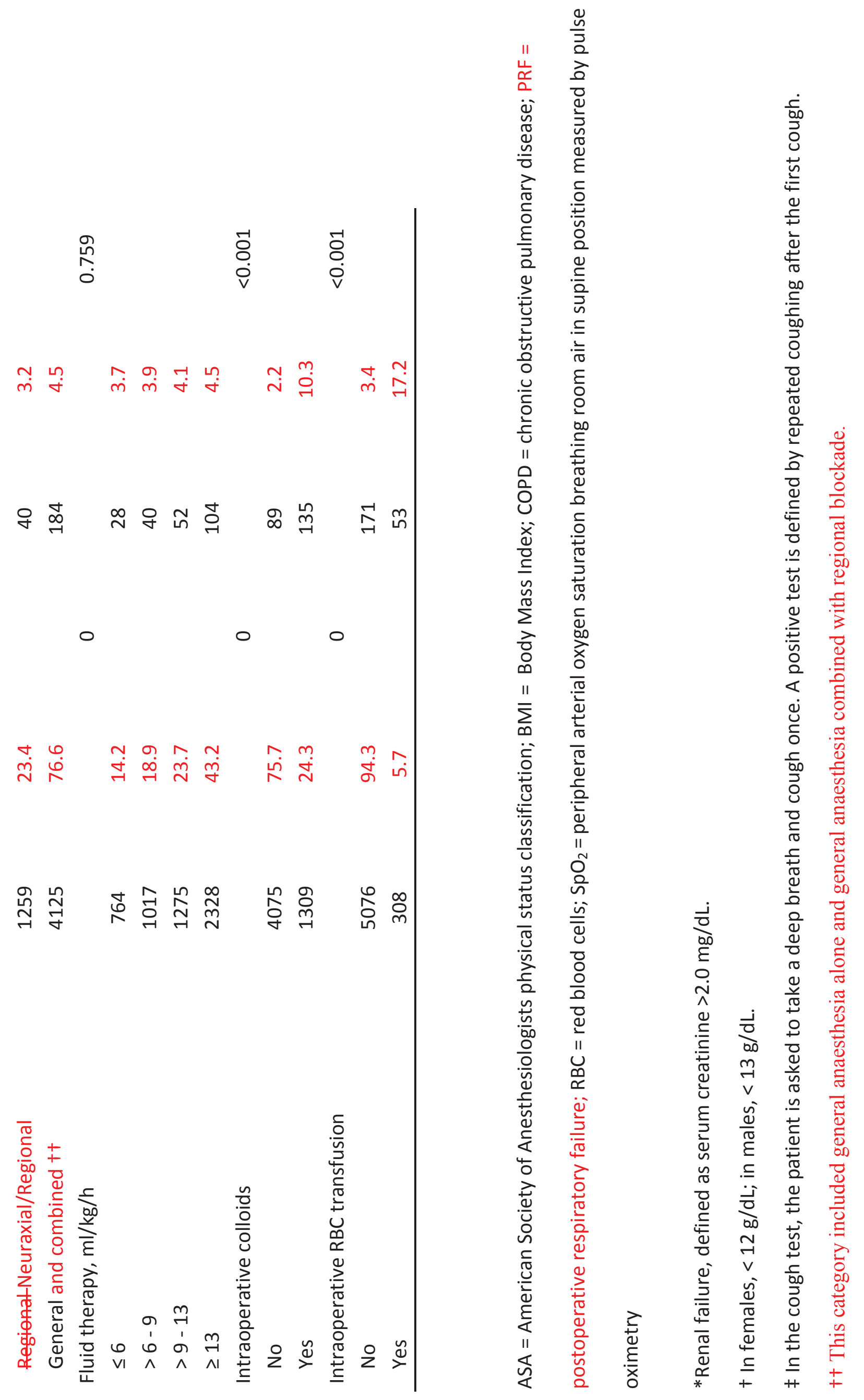




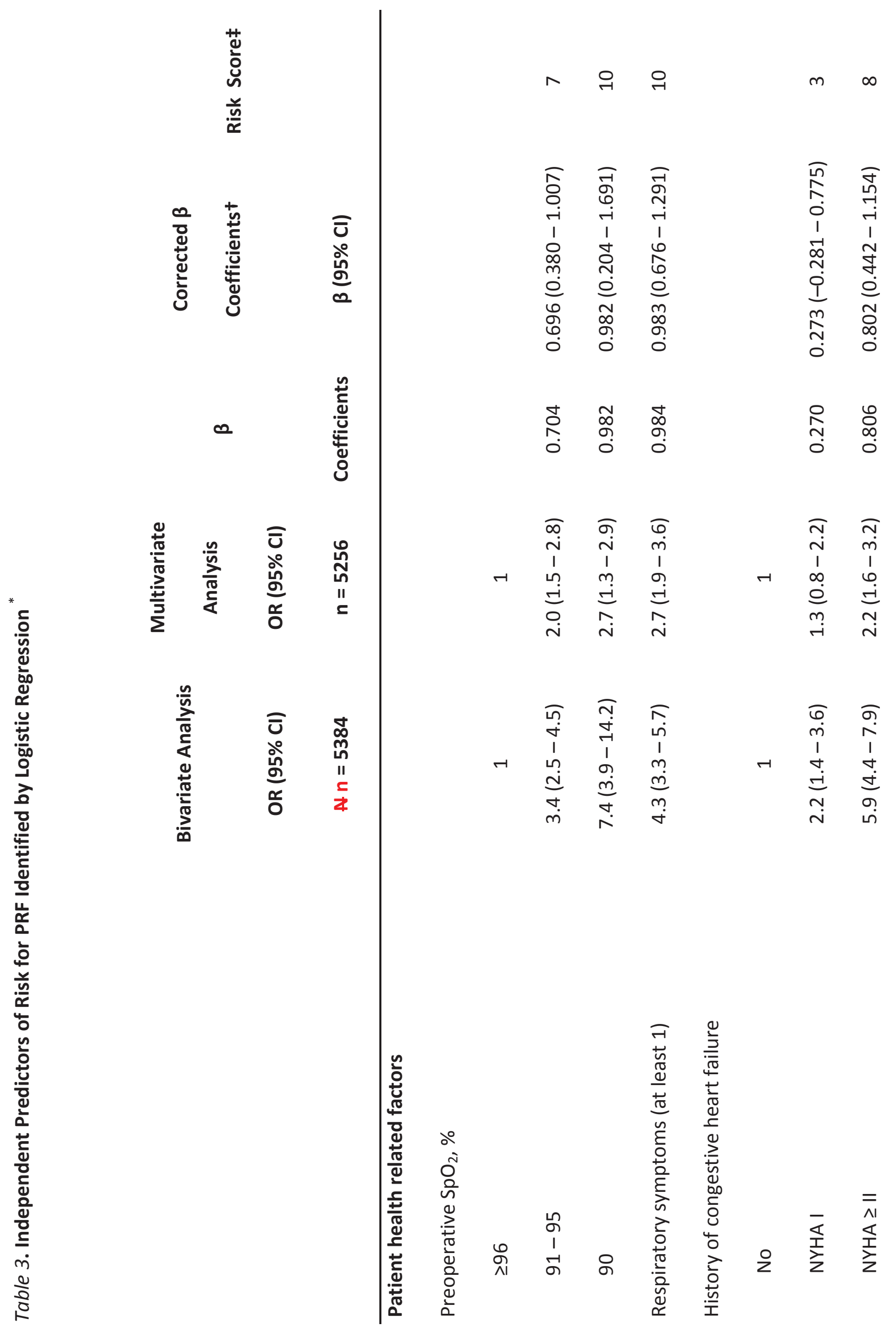




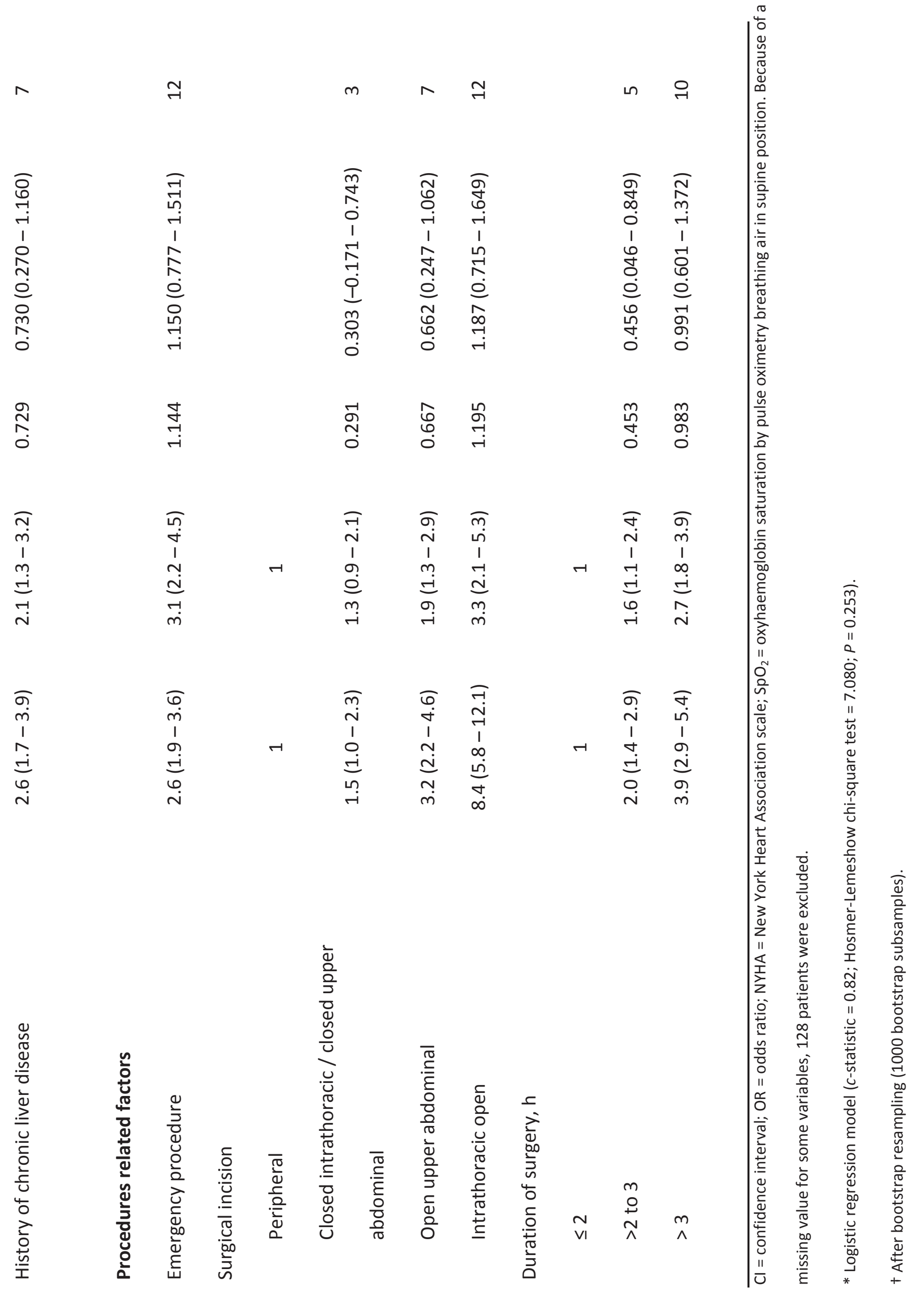


Table 4. Sensitivity, Specificity, and Positive and Negative Likelihood Ratios for the Ability of the Simplified Risk Score to Predict Intermediate ( $\geq 12$ Points) and High Risk ( 223 Points)

Cutoff $\geq 12 *$

Cutoff $\geq 23 *$

Sensitivity

$84.6 \%(79.1 \%-89.1 \%) \quad 55.9 \%(49.1 \%-62.6 \%)$

Specificity

$63.3 \%(61.9 \%-64.6 \%) \quad 89.4 \%(88.6 \%-90.3 \%)$

Positive likelihood ratio

Negative likelihood

$2.3(2.2-2.5)$

$5.3(4.6-6.1)$

ratio

$0.2(0.18-0.33)$

$0.5(0.4-0.6)$

Positive predictive

value

$9.1(7.9-10.5)$

$18.8(15.9-21.9)$

Negative predictive

value

$98.9(98.5-99.3)$

$97.9(97.4-98.3)$

* Data between parentheses are $95 \%$ confidence intervals. 


\section{Eligible patients \\ 409 patients lost for recruitment \\ 162 because they declined to give consent \\ 32 because they were already participating in another study \\ 44 had physical or cognitive deficits that made participation difficult \\ 21 were admitted at times when staff could inform them \\ 27 because of delayed or cancelled surgery \\ 13 because of early discharge \\ 33 for errors in the recruitment procedure \\ 8 in life-threatening situations that made informed consent impossible \\ 5 because they were given other types of anaesthesia \\ 64 for unrecorded reasons}

\section{Case record forms created}

35 patients excluded for protocol violation

30 because informed consent was obtained after surgery

5 because surgery date performed outside of the recruitment week

\section{Patients includede}

\section{1 lost to follow-up}

5384 Participants 

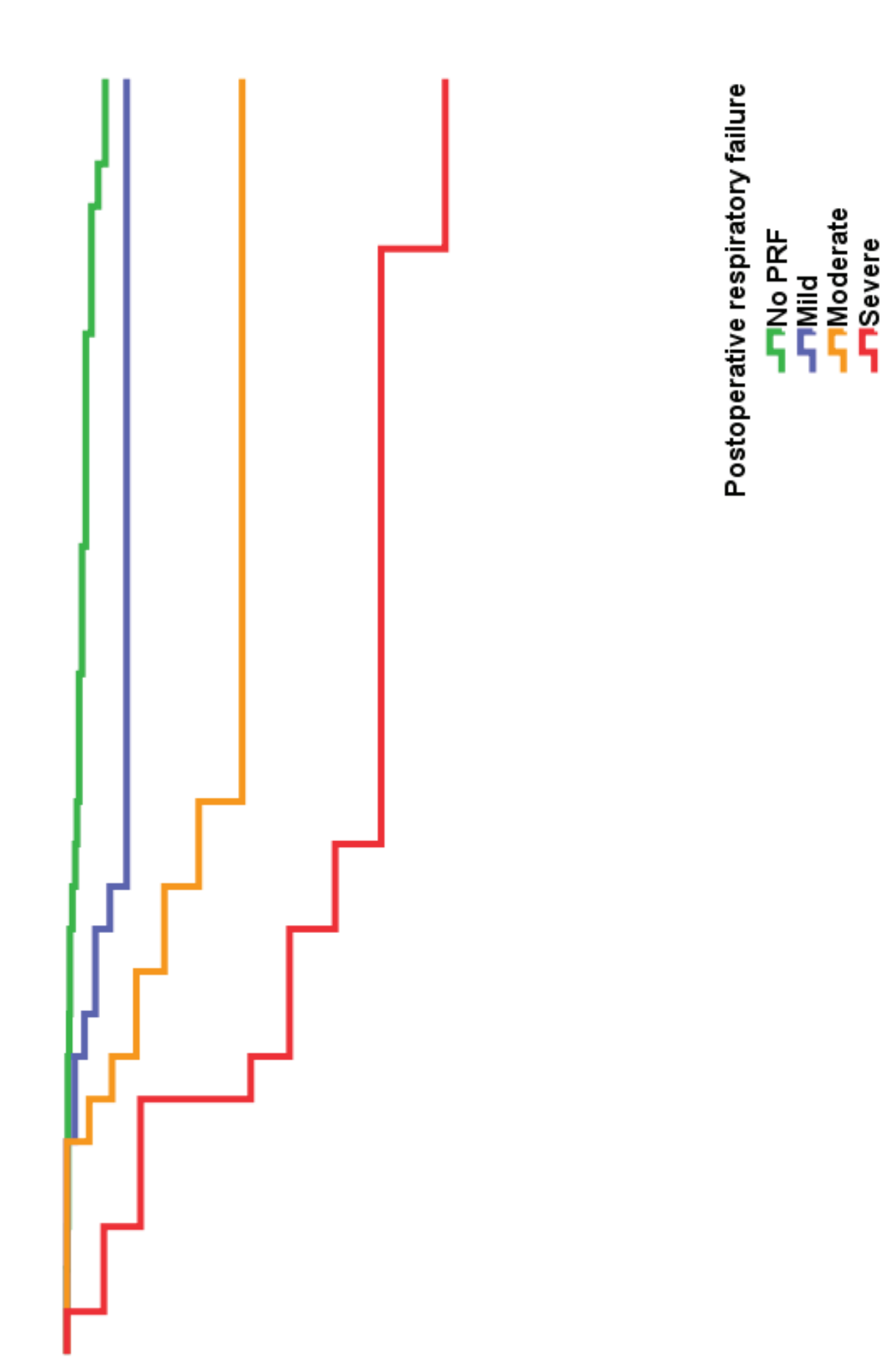

-요 역

-

(2) J

남ำ

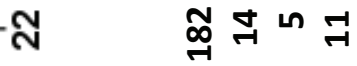

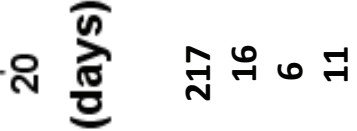

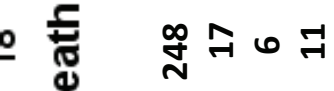

육

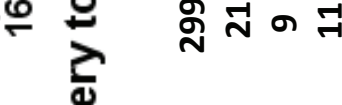

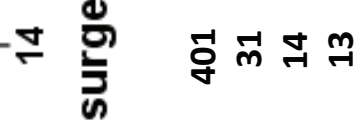

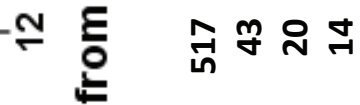

으 릍 영 윤유

$-\infty \quad$ \%

윧융요 처

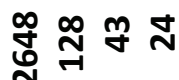

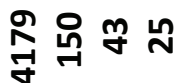

$-N$

运赑 宇 
